\title{
La investigación en comunicación y publicidad: nuevos temas y problemas
}

Juan Benavides Delgado | juanbenavides@ccinf.ucm.es

UNIVERSIDAD COMPLUTENSE DE MADRID

Resumen: En los últimos treinta años, la comunicación y la publicidad han cambiado de un modo profundo tanto en sus prácticas profesionales como en las líneas de investigación que se han desarrollado en el ámbito académico. Estos procesos están generando en los profesionales y en la propia sociedad nuevas formas de comprender la comunicación, que se están trasladando a generaciones de estudiantes y profesionales en la línea de conformar una sociedad más proporcionada, equitativa y justa. El objetivo de este artículo es realizar un breve resumen de los temas de de investigación en comunicación, tanto audiovisual como publicitaria, lo que proporciona una inestimable información para comprender qué sucede realmente en la sociedad mediática.

Palabras clave: comunicación, publicidad, empresa.

Abstract: In the last thirty years, communicarion and advertising have changed in profound ways both in their professional practices and in the academical research. These processes are generating new forms of understanding communication by professionalds and society, and also by new generations of students and professionals, on the line to form a more proportionate and fair society. The purpose of this paper is a brief summary of the research topics in communication, both audiovisual and advertising, providing an invaluable information to understand what actually happens in the media society.

Key words: communication studies, advertising, business. 


\section{Palabras preliminares}

Hace apenas unas semanas recibí un texto de la AEIC en el que se censuraba con toda razón el Proyecto de Real decreto por el que se establecen los requisitos básicos para la creación, reconocimiento y funcionamiento de universidades y centros universitarios y se determina su estructura mínima; un texto donde incluye solamente el Área de conocimiento de "Periodismo e Información" y se excluye un área fundamental como es la de Comunicación Audiovisual y Publicidad. Después de tantos años y de tanta investigación realizada resulta cuando menos un disparate regresar a debates de hace veinte o treinta años cuando la comunicación se asociaba exclusivamente al periodismo.

Dejando a un lado los argumentos del comunicado de la AEIC, con los que estoy de acuerdo, no quisiera dejar de reflexionar sobre los contenidos que se derivan del mencionado proyecto que, a mi modo de ver, expresan un disparate de magnitud, más propio de la ignorancia de lo que está sucediendo en el mercado y en la sociedad. Argumentos que desconozco si son la consecuencia de malsanos intereses políticos, pero que, en todo caso, habrá que desenmascarar por el daño que pueden ocasionar a las titulaciones actuales en Comunicación Audiovisual y en Publicidad. Una situación patética que esperemos, -siempre pensando en las generaciones que nos siguen-, no llegue a cumplirse. En base a este deseo, he decidido trasladar a esta publicación parte de una conferencia que pronuncié hace unos meses en la Universidad de Sao Paulo en debate con colegas investigadores de diversas universidades de América Latina sobre el futuro de la publicidad en España, con el fin de destacar como en el ámbito de la investigación en comunicación audiovisual y publicidad conviene continuar profundizando y no limitando; pues resulta imprescindible poner sobre la mesa todo ese conjunto de cuestiones y problemas que actualmente rodean a las personas y organizaciones en el ámbito la comunicación y la vida cotidiana. La verdad es que la salida de esta profunda crisis que padecemos requiere líneas de trabajo bien definidas y configuradas y no supresión, -o lo que es peor: falta de definición-, de áreas de conocimiento. En estos últimos treinta años la comunicación y la publicidad ha cambiado de un modo profundo tanto en sus prácticas profesionales como en las líneas de investigación que se han desarrollado en el ámbito teórico y académico. Estos procesos están generando en los profesionales y en la propia sociedad nuevas formas de comprender la comunicación, que se están trasladando a generaciones de estudiantes y profesionales en la línea de conformar una sociedad más proporcionada, equitativa y justa. Mi deseo en las líneas que siguen es hacer un breve repaso de aquellas áreas temáticas y de investigación que en la comunicación audiovisual y publicitaria proporcionan un inestimable conocimiento para comprender lo que realmente sucede en la sociedad de los medios y que, probablemente en pocos años, determinarán muchos de los procesos de comunicación que se ejercerán en el ámbito de la vida pública y personal de los ciudadanos. 


\section{Introducción}

Hace ya más de veinte años comenzamos en la sede de la Universidad Internacional Menéndez Pelayo de Cuenca una serie de seminarios y cursos sobre publicidad con una preocupación muy específica: el cambio que ya se observaba en la práctica publicitaria. Ciertamente en aquellos corrillos apenas si se hablaba de marca, el producto era el rey de las estrategias del anunciante y no existía la empresa porque la agencia reinaba sobre todo lo creado, el ciudadano era un concepto abstracto llamado target y apenas si se hablaba de Internet o de la ciencia ficción de los móviles. Publicidad era sinónimo de creatividad y los que procurábamos introducir la palabra comunicación éramos tachados a modo de insulto cariñoso de intrusos metodólogos. Sin embargo, -citando la célebre estrofa de Bob Dylan, -la respuesta está flotando en el viento-; y aquellas actividades si atendieron un poco aquella sensación de transformación del entorno profesional y académico.

Más allá de las reticencias de algunos sectores de la profesión, aquellos cambios se empezaron a producir y de que manera; y hoy en este ámbito de la publicidad vuelve a suceder lo mismo que antaño o, si se prefiere, no hemos dejado de cambiar desde entonces. La preocupación por lo que está por venir sigue en la cresta de la ola. Y lo que tiene que venir vendrá, como sucedió con el Director de Comunicación a principios de los noventa del siglo pasado, -el DIRCOM: aquella figura que se observaba por los directivos empresariales con suspicacia y una reserva no exenta de miedo (J. Benavides, 1994)-, o con los cambios en la agencia y, por supuesto, con Internet. La verdad es que en el ámbito de la Universidad esta preocupación ha estado siempre muy presente, -pese a las reticencias de algunos colegas que siguen en el erre que erre de hace veinte años-, y prueba de ello son las numerosas colaboraciones que siempre hemos mantenido con el universo profesional y que pueden verse reflejadas en investigaciones, cursos, seminarios especializados, etc., y todo el conjunto derivado de publicaciones y ediciones que hemos elaborado a lo largo de estos últimos años .

Después de haber finalizado varias investigaciones sobre el anunciante y la comunicación de las marcas (J. Benavides, et al. 2010) me parece importante escribir unos cuantos renglones, donde procuraré resumir mis opiniones sobre los cambios que se están produciendo en la publicidad española; unos transformaciones, todo hay que decirlo, rápidas y profundas y que están afectando al propio funcionamiento de la empresa y especialmente al modo en que las personas están construyendo cognitivamente las organizaciones y su comunicación. Algo que atiende a la publicidad de un modo directo y al propio mercado que en España se encuentra muy atomizado y con falta de referencias institucionales claras y precisas (agencias, centrales, institutos de investigación, etc.). A mayor abundamiento, parece que la crisis económica y financiera se ha extendido a todos los modelos de gestión corporativa y comprensión de la realidad, expresando la vivencia real de un cambio de paradigma que afecta a todos los niveles de la comunicación. 
Dada la complejidad y amplitud del tema voy a estructurar los contenidos en torno a varias cuestiones fundamentales sobre las que entiendo giran las preocupaciones cruzadas de empresas, anunciantes y agencias en estos primeros años del siglo XXI: dos grandes ideas básicas en torno a los anunciantes, las marcas y los nuevos escenarios sociales, donde la comunicación y las nuevas tecnologías ponen todo esto en relación; una tercera cuestión sobre el nuevo papel de la publicidad como herramienta de la nueva cultura; y, por último, cómo están reaccionando las agencias (en su sentido más general) y las funciones que deben cumplir las universidades ocupadas del quehacer formativo. Creo que hacer un breve repaso a todo este conjunto de temas, aunque sea de un modo muy general, puede aclarar algunos de los problemas con los que se enfrenta actualmente la práctica profesional de la comunicación y su investigación.

\section{El tema del anunciante y la marca}

En la actualidad el Anunciante se encuentra cansado y desorientado, las marcas se ubican en nuevos escenarios de actuación no siempre reconocibles, las agencias van a salto de mata en la situación del sálvese quien pueda y los medios aquí y allá con preocupaciones excesivamente endogámicas y poco preocupadas de la información. La situación es cuando menos compleja y lleva tiempo; porque algunas de las reflexiones que siguen ya han sido reclamadas por algunos anunciantes sin una adecuada respuesta por parte de las agencias y de los medios de comunicación convencionales; especialmente la televisión. Me centro un poco en el anunciante y la marca y dejo para otro momento los otros temas.

La primera cuestión reside en la pérdida de protagonismo del producto en los procesos de comunicación. En efecto, el producto ha sido el eje de la comunicación publicitaria de los últimos treinta años; sobre el objeto o el servicio recaía toda la estrategia creativa y argumentos de la comunicación del anunciante. Por ello mismo, cuando en aquel momento, por ejemplo, en lo años ochenta del siglo pasado-, se hablaba de marca se estaba hablando casi exclusivamente de marca de producto. Las empresas se definían por sus productos y servicios; y eran los atributos de éstos los que determinaban y definían los valores de aquellas.

En la marca de producto el espacio social (cognitivo) de la marca queda definido en sus ámbitos de consumo; es decir, es en el mismo proceso del consumo del objeto donde se determina el circuito real de esa marca. Porque, en efecto, la personalidad de la marca de producto se caracteriza por los atributos reales, imagen y diseño del objeto o del servicio que disfruta el consumidor. Por ello mismo, la creatividad queda reducida al manejo de los atributos y posibilidades contextuales y de diseño del objeto; es algo como si dijéramos que queda más a la mano, porque todo es medible y tangible y siempre cabe observar sus efectos y cuantificarlos. En el fondo, la cientificidad de la comunicación publicitaria busca siempre este referente empírico que no deja de ser muchas veces el equívoco del corto plazo, cuando no una falsedad. Por ello la marca se define siempre en función de los 
atributos y diseño del producto a partir un sencillo reconocimiento de aquella por parte de los consumidores en los sectores primarios de gran consumo (alimentación, bebidas, etc.) y un corto plazo que es el que determina el eje estratégico de la comunicación.

Probablemente estas características han permitido que la comunicación comercial se haya refugiado en este modo de construir la marca, -principalmente, como acabo de decir, en el sector primario como por ejemplo el de la alimentación, bebidas o los medicamentos, donde los públicos requieren el efecto del producto en el plazo más inmediato posible-. Ciertamente la marca de producto ofrece al anunciante un tipo de comunicación al que se está muy habituado y del que se posee una larga experiencia, se conocen sus alcances, ventajas y límites. No cabe duda de que el producto o el servicio siempre estarán presentes en la comunicación de una empresa. Sin embargo, la cuestión es si la realidad de la comunicación del anunciante va por ahí o no se reduce ya exclusivamente a ese planteamiento.

Indudablemente la comunicación publicitaria de producto se constriñe al corto plazo lo que permite al anunciante un mejor conocimiento de los posibles errores cometidos y el alcance del riesgo en la inversión realizada. Pero sin embargo, con la comunicación de producto la empresa no queda definida en su identidad, gestión y gobierno corporativo, algo que en la actualidad es lo más demandado por la sociedad. El desarrollo de la comunicación se reduce a los aspectos más externos de la misma pero queda oculta la empresa y todo el conjunto de relaciones que la organización gestiona hacia dentro y hacia fuera de ella misma. Y este es uno de los temas que irrumpen en la novedad de los cambios en la comunicación y la publicidad (aspectos que llevan ya algunos años encima de la mesa de las consultoras y la investigación): la empresa misma y sus grupos de interés, -los llamados stakeholders (R.E. Freeman, 1984)-, que comienzan a exigir de las compañías y organizaciones un paso más allá de sus preocupaciones por el modelo de negocio y su retorno en beneficios (M.Morsing \& M. Schultz, 2006, pp. 323-338). Unos nuevos planteamientos que se trasladan desde los iniciales modelos de gestión de las empresas a los procesos de comunicación de las mismas, con todo lo que esto significa para la gestión de la marca y la propia publicidad que las compañías estén en condiciones de llevar adelante.

La definición convencional de marca se ha referido casi siempre al signo distintivo de un producto o de un servicio de la industria que lo diferencia de otros productos similares. Sobre la base de esta noción de signo se han venido desarrollando otras nociones derivadas como marca corporativa, institucional, de distribución, franquiciada...,etc. Pero la realidad del problema no reside tanto en esta definición como en los aspectos funcionales de dicho signo, es decir, cuando se observa el papel del valor de una marca en los complejos procesos cognitivos desde los cuales las personas comprenden y construyen una marca y la empresa define su posición en dicho proceso. Dicho de otro modo: la personalidad de una marca y su territorio de referencia. Precisamente es ahí donde los cambios que se están produciendo son enormes y muy rápidos y donde la empresa como un todo cobra un especial protagonismo. 
Una de las cuestiones principales que discuten las empresas anunciantes en torno a la marca es la dificultad en integrar y definir con claridad su valor y posicionamiento respecto a los ciudadanos y la propia competencia y hacerlo ofreciendo una imagen coherente, integrada, única, -y ahora responsable / sostenible-, de sí misma. Y ello porque en la gestión de marca se produce un proceso continuo que va desde la sociedad a la empresa y de ésta nuevamente a la sociedad; y este proceso es difícil de definir porque esta presente en los contextos cognitivos de las personas y en la conformación del discurso social publicitario; y ello tanto a título individual como colectivo o institucional y corporativo. Unos ámbitos inaprensibles más allá del lenguaje que los construye: ¿Cómo definir e integrar de una forma clara el valor de la marca en este proceso? Porque, en efecto, la dificultad de esta cuestión tiene que ver con el llamado ser de la empresa, que es una cuestión de identidad y que afecta al ámbito de las necesidades y los deseos. Por eso las empresas no tienen problema en hacer publicidad convencional pero si comunicación de marca que es algo más amplio y complejo porque se refiere a un circuito donde los referentes son variados; de memoria no menos de diez: empresa - sector - productos / servicios - experiencia - personalidadcompetencia - colectivos sociales - estilos de vida - ciudadanos individuales (Ver figura 1). Dentro de ese proceso circulan los llamados intangibles que son los que no sólo configuran y definen los valores de una marca sino el mismo ser de una empresa; intangibles que sufren complejos procesos de construcción y deconstrucción en los imaginarios sociales.

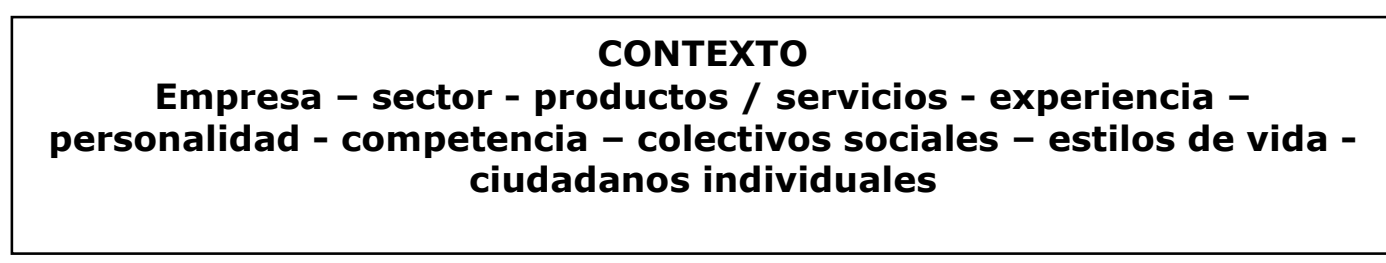

\section{IMAGINARIOS} SOCIALES

\section{PROCESOS DE CONSTRUCCIÓN SOCIAL DEL SER DE UNA EMPRESA EN LOS DISCURSOS SOCIALES}

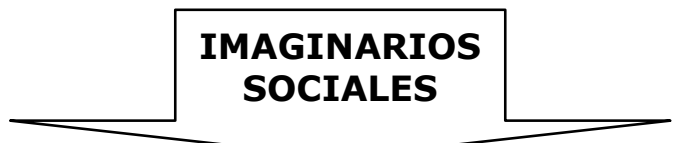

\section{GENERACIÓN DE CONOCIMIENTO EN TÉRMINOS DE "VALOR"}

Figura 1. El circuito de la marca corporativa. 
Dicho de un modo resumido, el circuito de la marca corporativa queda definido por las relaciones con sus grupos de interés y referentes sociales; este es el espacio social cognitivo de la marca corporativa. Las marcas conectan con las personas cuando ejercen sobre ellas ideas y les invitan a participar. Las marcas no pueden ser simplemente vendedoras: deben ser participativas y dar algo a cambio. Con este quehacer la personalidad de la marca se caracteriza por los valores de identidad de la empresa, sus necesidades, deseos y motivaciones y posibilidades que la convierten en un discurso de lo que es realmente; siendo el largo plazo el que determina el eje estratégico de la comunicación. Porque, en efecto, el desarrollo de la comunicación no queda reducido a los aspectos más externos de la misma sino que se extiende de forma coordinada a todos los ámbitos de la empresa. La comunicación marca ya no ofrece el producto sino que ofrece el ser de la empresa y su deseo de participar con las personas de sus objetivos a corto, medio y largo plazo. La publicidad y la comunicación de la empresa se convierte, -en palabras de un responsable de agencia-, en algo a cambio de algo; que no puede estar junto a la gente si duda de la gente o desconoce lo que la empresa realmente es y significa para la sociedad en la que está.

Esta nueva comunicación de la marca tiene unas indudables ventajas. Es cierto que funciona de forma diferente en relación con los sectores (siendo el sector servicios, -banca, energía, etc.-, el de mayor potencialidad y el de gran consumo, -alimentación, higiene, etc.,- el de menor implantación) y que exige una coordinación con las marcas de producto lo que no siempre resulta fácil. Pero sin duda favorece la identificación y diferenciación de la empresa, creando lazos emocionales con el consumidor y llegando a construir en el discurso social un espacio propio de proyección corporativa. Y en este momento introduzco con toda intención la noción de proyección corporativa que entiendo como el protagonismo cognitivo que una empresa puede llegar a tener en los discursos sociales. La proyección corporativa es la que determina en el medio plazo no sólo una adecuada reputación de la marca corporativa, sino, -lo que es si cabe más importante-, un reconocimiento social de la empresa en cuanto tal, que queda formulado en el propio discurso de las personas a título individual. A mi juicio el reconocimiento social de una empresa se sitúa, por tanto, por encima de su valor reputacional como marca y es uno de los nuevos valores que pueden llegar a ser determinantes en el papel futuro de una empresa sostenible y socialmente responsable (Figura 2). 


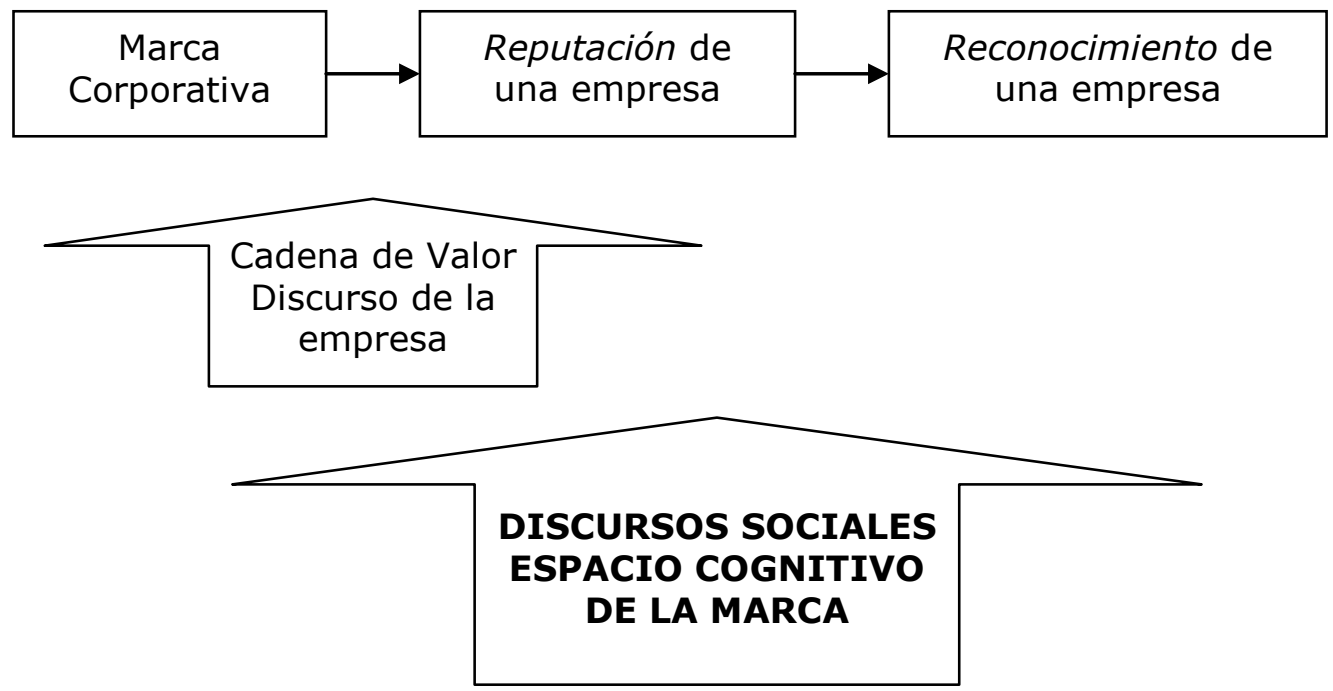

Figura 2: El espacio cognitivo de la marca corporativa diferencia varios niveles en los procesos de reputación y reconocimiento social de una empresa.

Todo este proceso, que acabo de resumir, explica el salto fundamental que a lo largo de estos años se ha producido en la creación y gestión de una marca: el paso de la marca de producto a la marca corporativa y lo que este paso está afectando a la propia estructura departamental de las compañías (en su momento este cambio supuso la introducción del Director de Comunicación y más recientemente se habla ya de una nueva figura denominada Chief Reputation Officer (CRO) (A. Alloza, 2010). Lo más interesante de todo este proceso no es al abandono de la marca de producto en su sentido más estricto, sino la integración de ésta en la nueva marca corporativa que se pretende más globalizadora e identitaria de lo que significa y representa la empresa en la sociedad y en el propio mercado. Que duda cabe que este salto ha cambiado la comunicación publicitaria y lo que es, si cabe, más importante: ha transformado la forma de comprender la comunicación de la empresa anunciante en su conjunto. Estas circunstancias explican las nuevas nociones que han aparecido en el ámbito de la comunicación empresarial; me refiero a conceptos como el de reputación, responsabilidad social o el más reciente de diplomacia corporativa, que no obedecen al capricho de nadie sino a las nuevas y reales obligaciones que están adquiriendo las organizaciones en los contextos de cambio que se experimentan en la actualidad. Circunstancias, todas ellas, que afectan a las rutinas del profesional de la comunicación y a los responsables de algunos departamentos de la empresa (como el de marketing), que no siempre entienden estos cambios o los observa con la mentalidad del empresario y del comunicólogo de hace veinte años. Lo que, a mi juicio, supone un error grave porque pone a la empresa a espaldas de la realidad. En este último sentido, cabe subrayar el esfuerzo 
encomiable de algunas empresas que frente a viento y marea procuran establecer un guía de buenas prácticas corporativas globales de acuerdo a una definición precisa de sus valores como marca y sus planteamientos estratégicos como empresa, más allá de los intereses coyunturales del marketing cortoplacista. Es un ejemplo de esto que digo la empresa SolMelia que en su última presentación de su Memoria de Sostenibilidad 2011 define con claridad todos los parámetros y exigencias de la nueva realidad con la que debe enfrentarse la organización en el siglo XXI. También cabe indicar la labor realizada durante más de diez años por el Foro de Reputación Corporativa y la propia Asociación Española de Anunciantes $(A E A)$, donde se han ocupado de modo directo de estas cuestiones, -a través de seminarios y cursos-, en la búsqueda de soluciones y alternativas.

Realmente lo que está sucediendo es que la marca se ha convertido en una idea que circula entre las personas y los colectivos sociales. Una idea que interesa y que implica a la gente. Dicho de otro modo: la marca corporativa es un camino muy complejo que construye objetos y sujetos, con el fin de hacer comprensivo el conocimiento que las personas tienen de las empresas y organizaciones. Las personas y colectivos sociales construyen, a su vez, la marca corporativa, ubicando a ésta en sus espacios cognitivos que determinan sus contextos perceptivos y de conocimiento. Todo ello supone un proceso interactivo donde el control de los valores por parte de la empresa no siempre es fácil: las marcas en su conjunto contribuyen a construir la realidad cotidiana del entorno de las personas, y éstas, a su vez, ponen en circulación aquellas en el ámbito de los discursos sociales.

Frente a la nueva situación comentada, el anunciante se sitúa en unas nuevas y complejas circunstancias comunicativas, que afectan directamente al modo de entender la comunicación publicitaria y a una preocupación cada vez más dirigida a lo que se empieza a conocer como la experiencia de la marca en el ámbito exclusivo de los públicos. Preocupaciones, todas ellas, que afectan, -como acabo de indicar-, desde la percepción y el modo de comprender la publicidad comercial hasta le propia organización departamental de las empresas, con una redefinición y reorganización de los propios departamentos de marketing y publicidad (AEA, 2008, p. 14).

\section{Los nuevos espacios sociales de la comunicación publicitaria}

Pero además de lo comentado sobre la marca, hacer comunicación en la actualidad significa sumergirse en un complejo escenario de naturaleza interactiva, donde todo esta presente y todo interviene: desde las organizaciones, compañías y empresas de medios, hasta los políticos y los propios ciudadanos a título individual o bajo el anonimato. Vuelvo a recodar aquí, aunque sea un momento, la noción de escenario a la que tanta veces he recurrido, porque realmente es lo que entiendo sucede en el ámbito de los medios de comunicación (convencionales y no convencionales) y la publicidad; dicho en dos palabras: la comunicación se debe entender no tanto como un proceso lineal de distribución de la información cuanto un "escenario interactivo" donde se desarrollan complejas prácticas culturales de 
institucionalización y legitimación social (J. Benavides, 2011). De esta noción derivan dos consecuencias claras: la primera se refiere al nuevo papel de las empresas, organizaciones (tanto públicas como privadas), los propios medios convertidos en grupos empresariales y, por supuesto, la responsabilidad de los ciudadanos en un ámbito donde la interacción tiene cada vez mayor protagonismo; y la segunda afecta al desarrollo de los nuevos espacios para la comunicación que la tecnología ha ido introduciendo como herramienta de la propia vida cotidiana.

Efectivamente este proceso de interacción ya se había iniciado en los años noventa del siglo pasado, con el desarrollo multiplicador de la televisión y la radio; pero sin duda el verdadero impulso lo ha dado Internet y la implantación de las redes sociales. No cabe duda de que los social media están transformando los roles de los receptores sociales convirtiendo a éstos en grupos activos de los propios procesos mediáticos. Lo digital se convierte, sobre todo, en una práctica más que en un uso, porque en internet son los usuarios los que cambian el modo de utilizarlo, convirtiéndolo en una forma de entender la vida, el tiempo y los espacios de su entorno cotidiano. Si se hace un breve repaso a la reciente evolución de Internet se puede entender esto que acabo de decir: En la llamada web 1.0 el medio se entiende como un espacio donde se consumen contenidos y en la web 2,0 es el usuario el que interviene y genera contenido. Pero ya en la web 3.0, -evolución de la anterior-, la gran protagonista es la movilidad: la libertad del usuario para utilizar Internet en cualquier momento y hacerlo a su gusto y manera, de acuerdo a las intenciones de cada individuo. Por eso las redes sociales y el propio internet no son tanto una tecnología cuanto una nueva filosofía a la hora de comunicarse y generar conocimiento; es un modo de pensar a través de la movilidad y el cambio, y especialmente a través de la generación y alternancia de contenidos, donde los individuos a título personal se convierten en los verdaderos protagonistas de la comunicación. Y lo más interesante: el contexto digital ha introducido un nuevo lenguaje, una forma de hablar donde las empresas y organizaciones sociales deben introducirse con sus marcas y con sus estrategias. 


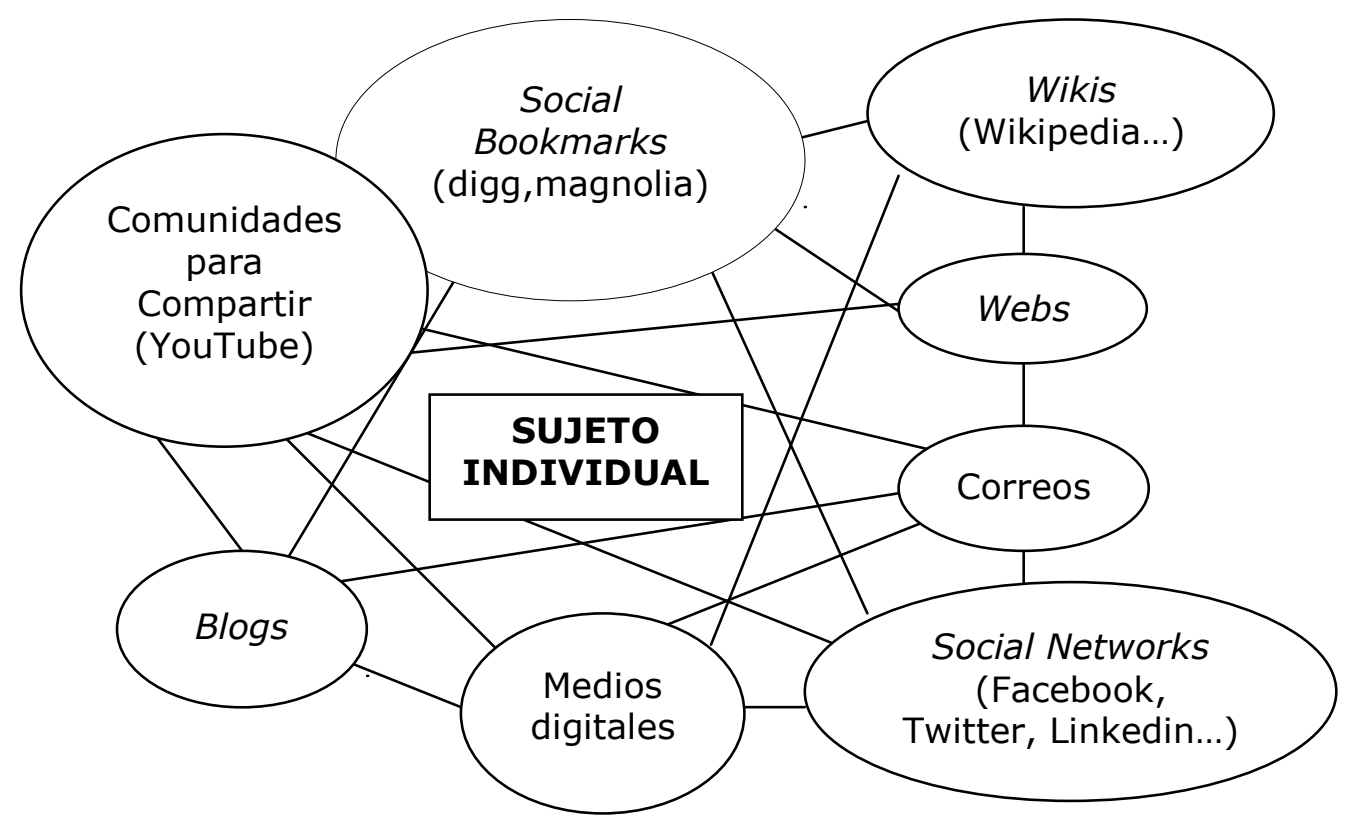

Figura 3. Nuevo modelo: A través de Internet se construye un nuevo ecosistema donde la comunicación fluye de modo interactivo y los contenidos se acumulan de forma diferenciada y cambiante.

El ámbito de lo digital ha construido un nuevo ecosistema social (Figura 3) que está sustituyendo al antiguo determinado por los medios convencionales y los emisores sociales instalados en un anónimo y direccional poder político. Muy al contrario de lo que antes sucedía, en este momento la personalización de las redes sociales ha situado en un mismo nivel a emisores y receptores, obligados ambos por la propia interactividad y libres de estar e intervenir donde se desee. Sin duda se observa un cambio en la génesis de una opinión pública, cada vez más fragmentada, desestructurada y determinada por cambios coyunturales, imprevistos e incluso caprichosos.

En este nuevo ámbito la empresa - anunciante se encuentra en contextos de poco control respecto a sus marcas y en situaciones de cierta debilidad en lo que afecta a su reputación, a los mecanismos de comunicación que deba establecer y especialmente al modo en que debe conectar con sus públicos y gestionar sus contenidos.

¿Y la publicidad? al principio procuró hacer lo mismo que ya hacía con éxito en los medios tradicionales, pero al poco tiempo ha tenido que cambiar y en cierto modo ha procurado salvar los muebles en el día a día; porque en efecto, Internet ha cambiado la creatividad publicitaria, el tiempo, el espacio y el modo de comprender los propios contenidos que se introducen. Pero la realidad del momento es que la actividad publicitaria no va mucho más 
allá de la buena ocurrencia momentánea y la empresa no sabe como situarse en ese nuevo ecosistema.

Pero, como acabo de decir, las marcas desconocen mayoritariamente estos nuevos ámbitos que superan lo conocido en los medios convencionales. Estos nuevos espacios obligan a revisar el propio marketing y sus viejos paradigmas (me refiero a las $4 \mathrm{p}$. del mk: producto, precio, promoción, planificación) y donde las marcas conviven en un entorno donde los usuarios, los medios y las empresas establecen relaciones fáciles y cómodas para todos. En estos contextos la publicidad que pueda hacerse no recurrirá tanto a los spots cuanto a nuevos formatos donde se desarrolla de modo más directo la emoción, los contenidos, las relaciones y colaboraciones y el propio desarrollo tecnológico que a todos esta en condiciones de proporcionar ventajas y beneficios. La publicidad procura construir emoción y motivación, siendo sus valores más recurrentes la creatividad cambiante y una colaboración constante con el usuario. La práctica publicitaria construye unos valores que vienen dados mas por las acciones que por las ideas, reducidas éstas a una creatividad muy poco duradera.

Parece claro que los cambios producidos por el desarrollo tecnológico se van a consolidar en los próximos años; pero lo más importante si cabe es que se está produciendo una falta de coincidencia entre el universo del contexto digital y el universo de la vida cotidiana; y las marcas buscan nuevas formas para ponerse en contacto con las personas; se están multiplicando los universos de la vida cotidiana y el individuo pasa de uno a otro con rapidez y capricho. La situación no resulta fácil en la búsqueda de propuestas rápidas y soluciones adecuadas a los problemas.

\section{La racionalidad publicitaria como herramienta cultural}

Pero al tiempo que se produce la revolución digital cabe hacer una reflexión en paralelo; precisamente la que se refiere a la práctica misma de la publicidad en el ámbito de la sociedad en su conjunto. Porque sigue habiendo publicidad en medios convencionales y sus formatos se multiplican de modo indefinido introduciéndose en todas las facetas de la vida cotidiana de las personas, hasta en sus aspectos más mínimos y de detalle.

Hasta hace unos pocos años, hacer publicidad significaba exclusivamente hacer anuncios; pero en la actualidad la práctica publicitaria va mucho más allá de lo que significa una campaña al estilo tradicional; sus técnicas y lenguajes son útiles para otros formatos de comunicación que utilizan los medios y los políticos de cara a determinar otro tipo de comportamientos sociales. Y esta última afirmación no significa que la publicidad deje de hacer anuncios, significa que su actividad se extiende a la práctica habitual de los discursos sociales, y por ello, es una actividad que no sólo afecta a la estrategia de un producto y a la creatividad asociada a dicho objeto, sino que determina la generación de los propios discursos desde los que el sujeto individual y los colectivos sociales interpretan su quehacer diario y su modo de comprender el entorno. Como ya he indicado líneas arriba, lo que ha cambiado son los escenarios sociales donde los medios de comunicación y los grupos sociales 
intervienen e interactúan. Y lo vuelvo a repetir: ya no hay direccionalidad desde un emisor a un receptor, sino complejos procesos de interacción donde los grupos sociales y los propios sujetos individuales tienen un progresivo protagonismo.

Todo esto significa que la publicidad contribuye de forma muy directa y protagonista a institucionalizar la vida cotidiana de los grupos sociales. Por ello mismo, -ya he comentado en otros lugares-, la práctica publicitaria se debe comprender y analizar como un fenómeno transversal que estructura comprensiva y comunicativamente la actual sociedad que vivimos; y consiguientemente, su actividad afecta a la comunicación mediática en su conjunto e incluso a la cultura de un país; al meno así lo observo en España.

Ahora bien, ¿Cuál es el alcance real de estas últimas afirmaciones? Precisamente la confirmación de que la práctica publicitaria es algo más que una práctica comercial que exige nuevos fundamentos y precisiones terminológicas. No tengo espacio en el presente artículo para un desarrollo pormenorizado de estos aspectos, pero trazaré algunas breves pinceladas que permitan al lector encuadrar el tema.

Vamos por partes. La publicidad facilita los modos de expresión, retóricas, recursos lingüísticos, incluso imágenes, „,, para protagonizar cualquier evento o acontecimiento social. No cabe duda, de que en los últimos ochenta o noventa años la publicidad inventa un modo de decir las cosas y expresar los problemas, que ha llegado a ser utilizado por las personas e instituciones en su vida diaria. Esto ha convertido a la publicidad en una forma de expresión y por ende casi en una forma de pensar y comprender el mundo, porque proporciona al individuo sentidos y conocimiento, hace compartir valores con las personas y simplifica la realidad formulando experiencias y prescribiendo comportamientos sociales y estilos de vida. Esto que se dice pronto tiene sus consecuencias, porque significa que la publicidad ha pasado de ser una exclusiva herramienta comercial de las empresas a ser una forma de racionalidad utilizada en la sociedad como argumento legitimador de comportamientos y estilos de vida. Porque, en efecto, a través de la publicidad accede el individuo a todo un conjunto de creaciones simbólicas y de sistemas de representación que determinan los procesos de construcción social de la vida cotidiana de las personas y los colectivos sociales. Estas últimas afirmaciones son un paso más a la afirmación de V. Verdú (2003, pp. 47, 70-73 y 143), según la cual la publicidad lo integra todo; desde esta nueva perspectiva, diría que la publicidad lo construye todo: es el fundamento de los procesos de construcción social de la realidad.

Como consecuencia de lo dicho, en este momento, hay que olvidar ese concepto de que la publicidad significa hacer anuncios y entenderla como lo que realmente es y significa: una Industria Cultural que utiliza sus herramientas y recursos comunicativos no sólo en la promoción comercial de productos y servicios sino en la construcción y legitimación de discursos sociales que afectan a la vida de las personas. Según esta visión, la publicidad como Industria Cultural es un concepto difuso que se refiere a todo ese conjunto de procesos constructivos y de distribución de conocimiento social. Desde un planteamiento parecido 
aunque con marcadas diferencias, V. Verdú (2003, p.126) define la nueva situación desde el concepto de capitalismo de ficción: Para este autor, en la actualidad el capitalismo se reblandece y los centros urbanos se convierten en artilugios recreativos clonados por la tecnología y dirigidos al entretenimiento y la aventura. Valores como la Información, experiencia (entendida como percepción de nuevos espacios para el disfrute), disfrute, imagen, comunicación, emoción, individualismo en grupos fragmentados, cambio en la ubicación del poder se convierten en el eje de la vida cotidiana Con todo hay que indicar que otros autores definen posiciones cercanas que deben estudiarse comparativamente; me refiero a autores tan diversos como M. Foucault, R. Barthes, J. Baudrillard, P. Sloterdijk o G. Gluksmann.

Asimismo y como consecuencia de todo lo dicho, los procesos de convergencia multimedia y la producción y el control de los contenidos se ha convertido en una de las claves de la publicidad y por ende del mundo de los actuales escenarios comunicativos. Y de la misma manera que las industrias culturales difunden signos, imágenes, sonidos, relatos y valores en los imaginarios sociales, la publicidad contribuye a legitimar el sistema, los subsistemas e instituciones sociales que constituyen nuestro entorno. La actividad publicitaria como Industria Cultural se ha convertido en una actividad transversal en los procesos estratégicos de las organizaciones sociales, instituciones y empresas; lo que supone una actividad de profundas consecuencias para la vida política, económica y social de España.

\section{Hacia dónde van las agencias y la industria publicitaria}

Parece claro que si la publicidad ya no es lo que era y el anunciante y la marca están viviendo en unos innovadores escenarios comunicativos, las agencias y el mercado deben pensar las nuevas situaciones. Y de entrada, la verdad es que la agencia lo tiene difícil.

Hay que indicar al menos dos aspectos previos: el primero que el sector publicitario está muy atomizado por lo que sus representantes no siempre coinciden en sus objetivos y posibilidades; y el segundo que el mercado ya no se define por su estabilidad o inestabilidad sino porque están cambiando sus referentes convencionales determinados por la oferta, la demanda y el beneficio. Ubicar la estrategia de comunicación de una organización en el ámbito exclusivo de estos tres parámetros se equivoca, porque el circuito de la comunicación debe atender también a cuestiones que afectan más al largo plazo, donde el papel activo de los individuos es coactivo respecto a lo que significa el retorno y la eficacia de una campaña.

Comento estos extremos porque a mi modo de ver hay que subrayar que la actual crisis económica, definida por muchos como una crisis sistémica y por ello como una quiebra de modelos en su sentido más amplio, ha puesto sobre la mesa y de modo incontestable la estructura inmoral y la falta de valores del propio sistema económico - financiero. $Y$ esta última afirmación no es una cuestión baladí; muy al contrario expresa la toma de conciencia clara por parte de la sociedad de que las cosas y algunos de los fundamentos en la toma de decisiones económicas y modelos de gestión deben cambiar de raíz. La importancia de esta 
situación exige tiempo, debate, prudencia y una claridad que no siempre se tiene; incluso se debe huir de cuestiones y conflictos ideológicos, porque, a mi modo de ver, la solución de la crisis económica no es en absoluto una cuestión de derechas o de izquierdas. Todos estos planteamientos forman parte del pasado y deben ser cada vez menos protagonistas en el futuro. Por otro lado, que duda cabe que estas afirmaciones también afectan al propio mercado publicitario y exige de éste nuevas ideas y argumentos, porque pensar, -como ya ha dicho más de uno-, que la publicidad es hoy una expresión exclusiva del mercado capitalista no sólo es una equivocación sino una simpleza. Incluso si se retoma el concepto del capitalismo de ficción de V. Verdú, cabe pensar, -como se indica en su propia definición-, que del modelo del capitalismo de producción y consumo solo queda el polvo.

Después de lo que acabo de indicar sobre la publicidad como industria cultural, la práctica de la comunicación se enfrenta a nuevos retos que afectan directamente a la propia responsabilidad social de su quehacer. Hasta hace relativamente poco tiempo cuando se comentaba la ética de la publicidad su referente eran siempre los contenidos de los anuncios; era una ética puramente instrumental basada en la contextualización de los contenidos de un relato (J. Benavides, 2004, pp. 81-130). Sin embargo, los nuevos compromisos parece que apelan a cuestiones más estructurales y por ello, hablar de ética o de responsabilidad social de la publicidad conduce a pensar irremediablemente en la estructura del mercado, sus objetivos y sus posibilidades de cara a la consecución de una sociedad más equilibrada, equitativa y justa. La publicidad debe ayudar al anunciante a gestionar su marca y hacer posible y viable un modelo de negocio, dándole transparencia y legitimidad social; y si se trasladan estas preocupaciones a la comunicación política, -donde normalmente lo que hay es una ausencia casi absoluta de ética-, deberían abandonarse todo ese conjunto de viejas rutinas que la han convertido en una comunicación dañina para la sociedad y vergonzosa para el político.

Todas estas reflexiones, han llevado al anunciante y a la propia agencia a cambiar la inmediatez de sus rutinas y trasladar todas y cada una de sus acciones a un proyecto general donde la estrategia, la creatividad y el propio contenido de un plan de comunicación permita una relación adecuada de la empresa con sus grupos de interés y con el conjunto de la sociedad: hay que trasladar la gestión comunicativa de abajo arriba, de la gente a las organizaciones, de los productos a los valores. $Y$ ya puede decirse que hay agencias preocupadas con esta nueva filosofía donde el problema de la persona o de un colectivo es el que se convierte en el eje de campaña, muy por delante incluso del propio producto. Aunque también es cierto que muchas otras agencias viven de espaldas a la realidad, ocupadas en lo exclusivamente suyo, con la errónea convicción de que los cambios son puramente instrumentales, que lo demás y lo de fuera no ha cambiado, que la mentalidad de las personas es la misma y que el sistema permanece inmutable. Que el hombre es malo por naturaleza y que lo que busca es vivir bien por encima de cualquier otra preocupación. Y aunque esto supone pervivir en el error, sus directivos nos hablan de las agencias digitales y de conectar con la gente a través de la emoción y de una especie de proceso de 
especialización comunicativa integrada. Cuando la verdad es que la agencia debe integrarse en la empresa anunciante; es decir, ser parte de ella y hacer de la comunicación de la empresa un todo unitario; lo cual significa la desaparición de la agencia de publicidad en el sentido como la hemos conocido para convertirse en una herramienta de gestión que la empresa utiliza de acuerdo a lo que determinan sus responsables de comunicación. La agencia y muchos de los referentes de la industria publicitaria deben darse cuenta de las preocupaciones de la calle y de los cambios que se están exigiendo en los modelos de comunicación; partiendo de ahí, unificar esfuerzos y abandonar los egoísmos cortoplacistas.

\section{El nuevo papel de la Universidad}

La cuestión de este último tema me afecta directamente. Ya hemos visto que los cambios del mercado publicitario son profundos: el anunciante vive desorientado y desconfiado, la marca en una cierta situación de descontrol, unos escenarios de comunicación interactivos donde el que manda es el individuo y una industria publicitaria fragmentada y sin saber realmente donde dirigirse y qué hacer. Y también hemos visto que hay empresas que se están tomando en serio estos temas y hacen de su comunicación algo más serio y global, fundamentándose en nuevos valores y persiguiendo una ética que les exige y obliga; aunque también hay otras, -todavía la mayoría-, que siguen instaladas en el marketing convencional como si esto de la crisis y lo cambios fueran una cuestión coyuntural del exterior, una tormenta de verano que lo único que exige es un buen paraguas y aprovechar las circunstancias.

Y ante este cúmulo de contradicciones y complejas circunstancias me vienen las preguntas: ¿Qué es lo que deben hacer las instituciones educativas como la universidad o las escuelas de negocio? ¿Para que sirven realmente? Y para mí la respuesta es clara: ofrecer ideas, soluciones y herramientas a las personas y los gestores de comunicación, que les ayuden en la toma de decisiones y en una visión más correcta de los problemas; y para ello, -apelando a lo que decía al comienzo de este artículo-, el área de conocimiento de la Publicidad y la Comunicación Audiovisual debe ser consolidada. Desde luego, todo lo contrario de lo que aparece en los presumibles proyectos de las autoridades del Ministerio de Educación Español que en lugar de ver la realidad y el futuro siguen anclados en unas reflexiones más propias de los años setenta del siglo pasado.

Llegados a este punto, permítaseme un breve paréntesis. El tema de nuestro tiempo se sitúa en un eje de debate extremadamente equivoco que se formula con una pregunta: ¿Qué es anterior, la idea o la conducta? En el pensamiento ilustrado el lugar que ocupaban las ideas siempre era anterior a la conducta, porque eran ellas las que daban razón de aquella. Sin embargo en la actualidad sucede precisamente lo contrario; los comportamientos se suceden con anterioridad a las ideas y se convierten en el molde de éstas. Por ello, hay tantas ideas como conductas y, lo que es más decisivo, hay tantas morales como comportamientos; lo que significa que el valor universal de la ética desaparece, quedando reducido a los diversos modelos emotivistas propios del sujeto liberal; y por ello también los valores se reproducen 
como los piojos o los pulgones, tan solo ocupados en comer y reproducirse. Sucede en la actualidad que el hombre actúa siempre por delante, como los micos, de forma reactiva.... Y luego si acaso piensa. Se ha cambiado poco desde que Ortega y Gasset planteara esta reflexión. Lo grave de esta situación es que las leyes parecen adecuarse a este nuevo modelo y se construyen no desde las ideas sino desde los comportamientos que convierten en ley los hechos consumados. Tamaña locura que solo puede llevar al hombre al disparate, - a ese no saber a que atenerse propio del miedo y la violencia-, y la sociedad a su disolución.

Frente a esta situación parece que hay que recuperar valores; pero el proceso no es fácil y tiene sus equívocos y contradicciones. Hace ya unos años retomaba este tema, reconociendo el origen del valor en la vida cotidiana y lo que supone en el cambio del modelo de empresa la introducción de esta reflexión; pero para que un valor tenga la fiabilidad necesaria requiere que sus contenidos expresen una solidez ética incuestionable, de lo contrario son papel mojado (J. Benavides 2007, pp. 57-76). En efecto, el valor es el molde, -al igual que lo fue el significante barthesiano-, que determina el conjunto de significados del discurso social respecto a un hecho, una conducta, un acontecimiento, una empresa, una organización o cualquier otra circunstancia. Por ello el valor se circunscribe a un discurso concreto referido a un fragmento de la vida social. El valor es cambiante, -pertenece a la cadena de los significantes-, y viene dado significativamente por las propias exigencias del imaginario social y determinado por los grupos sociales en el poder. La persona utiliza los valores que le sirven de nexo en su relación con la realidad que vive y experimenta. La verdadera dificultad aparece cuando se confunde la herramienta del valor con el contenido que pretende significar. Desde esa confusión el valor en sí mismo no es nada y tampoco tiene que ver con la realidad y mucho menos con supuestos fundamentos de verdad. El valor es una simple representación. Por ello no se debe confundir el valor con su significado porque puede generar relativismo y promover lo que ya Foucault explicara sobre el hombre: Una marca en la arena de la playa que se borra cada vez que pasa la ola por encima. En ese supuesto el valor sería lo único que quedaría como nombre y con eso solo el valor es nada. Hasta aquí el paréntesis.

Ciertamente esta situación que comento desemboca de modo inevitable en la anomia que no expresa otra cosa que la ausencia de normas y jerarquías morales, todas ellas reducidas al momento, a la coyuntura o a la hybris del sujeto. Si el significado pierde su enganche con el discurso de la cultura y sus fundamentos arquetípicos sólo el valor prevalecerá y entonces la anomia se situará por encima de todo. Y desde aquí vuelvo a las preguntas iniciales: ¿quién o qué esta en condiciones de ayudar a dar solidez ética a los valores de la comunicación? ¿Quién tiene autoridad para hacerlo? En cierto modo la ética civil ilustrada ha entrado en una vía muerta de consecuencias impredecibles y al tiempo parece imprescindible regenerar y potenciar la ética individual si queremos salir de esta.

Indudablemente es la universidad la que debe dar respuesta a estas preguntas y hacerlo a través de la investigación, el debate y mucho tiempo de reflexión. Pero la verdad es que las iniciativas de los responsables públicos crean mis dudas de que la universidad española esté 
en condiciones de cumplir esta misión. Se necesita como nunca de la investigación y el debate; y lo que sucede en el ámbito de la política universitaria es precisamente lo contrario. Con el nuevo modelo de Bolonia se multiplica, -en contradicción a sus principios-, la docencia en detrimento de la investigación; y lo que es peor, esta docencia no se desarrolla en las condiciones de calidad exigidas. $Y$ el que diga lo contrario falta a la verdad; al menos eso es lo que estoy observando en mi experiencia como docente. La actividad académica tendría que reducirse en favor de la investigación y las clases magistrales deberían desaparecer para convertirse en pequeños grupos de debate donde el profesor / investigador este en condiciones de definir opiniones y conceptos y poner en relación la reflexión académica con los problemas reales de la sociedad, de las empresas y organizaciones; y para todo ello, se necesitan más profesores. Solo así se estará en condiciones de desarrollar una formación integral y crítica, que es lo que se necesita para el futuro. Pero no hay dinero para financiar este nuevo modelo. Una verdadera pena. Llevamos años hablando de este problema y poco ha variado la situación; incluso se puede decir que ha empeorado: la universidad sigue desconociendo que hay partes de la ciencia que no pertenecen al laboratorio o a la pura técnica sino a la cultura; y lo que realmente se necesita hoy en comunicación es investigar en el ámbito de la cultura, lo que permitiría superar ideas fijas y, -por utilizar una noción clásica-, discernir los problemas. Se defiende en algunos sectores que la juventud actual es la mejor preparada en años, pero esto es solo una verdad a medias en la medida en que, -en el ámbito de la investigación en comunicación-, la especialización hace a veces más daño que bien.

Y vuelvo a las preguntas que requieren análisis y espíritu crítico: ¿qué tipo de ética estoy en condiciones de definir a la hora de hablar de valores como el de la sostenibilidad, responsabilidad social o diplomacia corporativa?; o centrándome en la práctica publicitaria: ¿hasta que punto el problema de la eficacia de la comunicación exige una reflexión previa sobre la naturaleza de lo que significa realmente ser eficaz? Porque, en efecto, lo más importante es el modelo que se tiene en la cabeza, que, si no cambia, las respuestas se repiten en un espacio lleno de vacío y no caben soluciones. Y para responder a estas cuestiones y otras muchas de la comunicación y la publicidad, se requiere mucha libertad, espíritu crítico y una formación integral e interdisciplinar de la persona. Todo un reto para el momento que vivimos y que no se si la Universidad está en condiciones de cumplir.

\section{Conclusiones}

He comentado a vuelapluma cinco temas, mejor dicho, cinco grandes áreas de cuestiones que, a mi modo de ver, no sólo determinan el futuro de la comunicación y la publicidad sino que exigen más investigación y estudio de cara a la solución de los problemas que en la actualidad experimentan las personas. La verdad es que apenas si he rozado los contenidos de fondo, pero he preferido hacer una reflexión general, que tiempo habrá de aterrizar en cuestiones más puntuales y concretas. Un conjunto de ideas que permitan precisar lo que significa y representa la práctica publicitaria en el ámbito general de la comunicación de la 
empresa anunciante y del conjunto de los referentes e instituciones sociales. Parece evidente que hay que cambiar las cosas, sobre todo las rutinas profesionales y esa especie de mentalidad, según la cual, la publicidad es una herramienta de comunicación direccional entre un anunciante $\mathrm{y}$ un público y unos medios que actúan como árbitros neutrales y difusores de la información, que permiten al anunciante ganar mucho dinero. El spot vale para lo que vale, y los anunciantes requieren de nuevas exigencias y obligaciones en esto de la comunicación.

En primer lugar, hemos visto la necesidad que tiene la empresa de trascender el producto en favor de una redefinición de su marca. Cuestión compleja, porque si se observan los aspectos cognitivos de los espacios de la marca aparece la importancia de definir su personalidad; y desde ahí se produce el salto del producto a la empresa que está detrás. Pero definir la empresa y su presencia en los discursos sociales significa atender a todo un nuevo conjunto de valores (intangibles) que determinan la personalidad de una marca y de la empresa que está detrás.

La personalidad de la marca se caracteriza consiguientemente por los valores de identidad de la empresa, sus necesidades, deseos y motivaciones y posibilidades que la convierten en un discurso de lo que es realmente como compañía; siendo el largo plazo el que determina el eje estratégico de la comunicación. Sin embargo pensar y definir valores no es cuestión fácil, porque lo importante es saber cuales son los significados de lo que se entiende por valor; y si estos significados no son precisos, transparentes y cumplidos por parte de las instituciones sociales, no serán creíbles por parte de los públicos; y las empresas serán doblemente criticadas por un uso inadecuado del marketing y de la imagen. ¿Quién o qué está en condiciones en el momento presente de ofrecer esos significados con autoridad $y$ credibilidad?

Pero sobre este conjunto de problemas se añade un segundo que se refiere a la naturaleza de los nuevos ámbitos de la comunicación, convertidos en escenarios donde los ciudadanos cobran un especial protagonismo; dicho de un modo claro: el consumidor toma el mando, se ha convertido en un ciudadano autosuficiente y autodidacta. Por eso las 4F's del marketing 2.0 de las que habla Kotler (2010) conducen a las marcas a plantearse el problema de la participación del usuario en la construcción y reputación de la propia marca. Es la pérdida de control de la empresa sobre sus marcas. Es la entrada del Marketing 3.0 y del CRO (Corporate Reputacion Officer) como nueva figura en la dirección de las empresas.

Pero este nuevo contexto supone para la empresa anunciante y su publicidad un segundo reto de dificultad, porque la creatividad no se reduce a hacer un anuncio, sino que se extiende a todo el conjunto de la planificación estratégica, donde el producto o los servicios quedan muy disminuidos respecto al conjunto de acciones que se deben realizar. Antes toda la comunicación publicitaria casi se reducía al claim creativo, sin embargo, en la actualidad la movilidad que produce internet y la intervención directa y personalizada del ciudadano hacen del insight un mero accidente del proceso. El anunciante sabe que se han roto los modelos 
de comunicación direccionales y la sociedad pide que su marca este en condiciones de definir rasgos y personalidad, sus espacios sociales y su gente; y consiguientemente, los contenidos se convierten en una de las piezas clave de todo el proceso. La publicidad no da propiedad de nada, sino que la marca busca construir y apropiarse de aquellos contenidos que son perseguidos o construidos, a veces del modo más arbitrario, por los públicos.

Frente a esta situación las agencias de publicidad, -al menos muchas de ellas-', se han mantenido, y por qué no decirlo, todavía se mantienen muy al margen de todos estos cambios. La industria publicitaria está muy fragmentada bajo el dominio de las mieles de algunas multinacionales que mantienen un cierto glamour de naftalina. Pero la realidad es mucho más dura de lo que expresan los libros de texto de las universidades y de lo que todavía se mantiene en debates y corrillos de profesionales y académicos. Probablemente este gap que habrá que superar en su momento más obedece al miedo o es producto de aquellas mentalidades ya acomodadas, que viven de espaldas a la realidad de lo que está sucediendo.

La agencia deberá asumir lo que significa la nueva estructura de mercado de la comunicación que poco a poco va empezando a definirse; una estructura donde los referentes son los ciudadanos, -no los consumidores-, y unas empresas cada vez más conscientes de su papel como organizaciones al servicio de la sociedad. En estos nuevos papeles, la ética reaparece dentro de categorías como la de la responsabilidad social, que aplicada a la actividad publicitaria trastoca la reflexión sobre la ética, trasladándola mas allá de los simples contenidos de un anuncio y ubicando la reflexión en lo que debe significar la comunicación estratégica de una marca, de un modelo de negocio y de una empresa.

Todo este conjunto de últimas reflexiones me llevan a romper una lanza en favor de la publicidad; pero de otra publicidad, no la de antes que ya ha sido, sino la del futuro, la que debemos definir entre todos, en el marco de nuevos modelos que emergen a nuestra derecha y a nuestra izquierda. Y, en definitiva, aquí reside el papel que la Universidad debe adoptar en la investigación y docencia de la comunicación y la publicidad: la preparación y educación integral de personas libres y críticas que, en la búsqueda de un cierto liderazgo, atiendan al llamado por algún autor índice de desarrollo humano (S. Hessel, 2011, p. 34) y lo sitúen por encima de la vieja idea del progreso o la más reciente de la innovación tecnológica.

Pero ni mucho menos esta todo perdido; el panorama no es tan desalentador como pueda parecer a primera vista. Mis comentarios son sinceros y obedecen en parte a lo observado directamente tanto en el ámbito de la academia como en la propia profesión. Sin embargo, en la línea de esta sinceridad debo también subrayar que algo de fondo se está moviendo en la empresa - anunciante, nuevas líneas de preocupación retoman lo que en algunos Foros se lleva debatiendo desde hace mucho tiempo y no parece que los esfuerzos de unos y otros vayan a caer en saco roto Me refiero por ejemplo a todo el conjunto de actividades que, desde hace años, organiza, -en el ámbito de la profesión-, la AEA, el Foro de Reputación 
Corporativa o el todavía más reciente Corporate Excellence, cuya presentación en sociedad fue hace tan sólo unos pocos meses; o el proyecto de "Marcas que Piensan", desde planteamientos más académicos, en el sentido de poner sobre la mesa algunas de las reflexiones que he comentado en este breve artículo. Son muchos los debates en seminarios y cursos, y no pocos los directivos e investigadores que llevan indicando soluciones y posibilidades de la comunicación de la empresa frente a los cambios; y parece que las horas de dedicación a todos estos proyectos van a tener sus buenos resultados. Los retos están ya sobre el papel y encima de la mesa; pero también hay muchas buenas ideas y personas. Esperemos de nuestros dirigentes políticos y educativos más responsabilidad y sentido de la realidad; es decir, conocer lo que está ocurriendo y actuar con ética y transparencia.

\section{REFERENCIAS BIBLIOGRÁFICAS}

AllozA, A. (2010): "De Maquiavelo a la Neurociencia: las marcas que queremos en La comunicación empresarial y la gestión de los intangibles en España y Latinoamérica. Informe 2010", Madrid, Prentice Hall, pp. 131-171.

Benavides Delgado, J. (2004): "La ética y los medios de comunicación en el ámbito de la cultura publicitaria. Una aproximación conceptual en Medios de comunicación. Información, espectáculo y manipulación", en J. A. Zamora (ed.), Navarra, Verbo Divino, pp. 81-130.

--- (2007): "La comunicación de los valores en las empresas y organizaciones en Evolución conceptual y práctica de una gestión responsable", en A. Bajo y N. Villagra (eds.), Madrid, Universidad Pontificia Comillas, pp. $57-76$.

--- (2008): "El estado de la comunicación en la enseñanza universitaria" en Comunicación y Pluralismo, 1, Salamanca, Universidad Pontificia de Salamanca, pp. 173 - 194.

--- (2009): "Ética y Crisis Económica en La comunicación empresarial y la gestión de los intangibles en España y Latinoamérica. Informa Anual 2009", Madrid, Prentice Hall, pp. 127 - 131.

--- (2011a): "La opinión pública y los medios de comunicación" en A. Hortal y X. Etcheverria (eds.), Profesionales y Vida Pública (A. Hortal \& X. Etcheverria, eds.), Bilbao, Desclee de Brouwer.

--- (2011b): "¿De dónde vienen los valores de las marcas?", Centro de Conocimiento sobre Reputación Corporativa (www.reputacioncorporativa.org). 
BenAvides Delgado, J. et al. (2008): "Los anunciantes españoles y el nuevo contexto de la comunicación: una aproximación cualitativa" en Revista Latina de Comunicación Social, 65, Tenerife, Universidad de La Laguna, pp. 159-175 (http/www.revistalatinacs.org/10/art/890_ucm/12_Benavides_et_ al.html).g

Benavides Delgado, J. y Alameda García, D. (2009): "¿Hacia donde va la publicidad?" en Comunicación y Pluralismo, 0, Salamanca, Universidad Pontificia de Salamanca, pp. $34-60$.

Freeman, R. E. (1984): Strategic Management. A Stakeholder Approach, Marshfield, M. A., Pitman.

GRunig, J. E. Y HUNT, T. (1984): Managing Public Relations, Fort Worth, TX: Harcourt Brace Jovanovich, College Publishers.

HATCH, M. J., Y M. SCHULTZ (2008): Esencia de Marca, Madrid, Lid.

HESSEL, S., (2011): iComprometeos!, Barcelona, Destino.

Kotler, P.; KARTAJAYA, H., Y SetiawAN, I. (2010): Marketing 3.0., Madrid, Lid.

MoRsing, M., Y SCHULTZ, M. (2006): "Corporate Social Responsability Communication: stakeholder information, response and involvement strategies", Business Ethics: A European Review, 15: 4, October, pp. 323 338.

Verdu, V. (2003): El estilo del mundo. La vida en el capitalismo de ficción, Barcelona, Anagrama.

VV.AA. (1993): Director de comunicación (J. Benavides Delgado ed.), Edipo Ed., Madrid.

VV.AA. (1994): Crisis de la Publicidad (J. Benavides Delgado, ed.), Edipo, Madrid.

VV.AA. (1997): El debate de la comunicación (J. Benavides Delgado, ed.), UCM, Madrid.

VV.AA. (2007): Evolución conceptual y práctica de una gestión responsable (A. Bajo \& N. Villagra, eds.) Universidad Pontificia Comillas, Madrid 2007, pp. 57 - 76

VV.AA. (2003): Públicos, instituciones y problemas en la comunicación del nuevo milenio (J. Benavides \& N. Villagra), UCM, Madrid.

VV.AA. (2004): Reflexiones sobre la responsabilidad social, la empresa y el Tercer Sector. Memoria Académica. Curso 2003-2004, (J. Benavides \& J.L. Fernández, eds.) Comillas, Madrid.

VV.AA. (2005): La comunicación de la Responsabilidad Social Corporativa. Memoria Académica. Curso 2004-2005, (N. Villagra, ed.), Comillas, Madrid.

VV.AA. (2006): La ética y la Responsabilidad Social de las Empresas y Organizaciones. Memoria Académica. Curso 2005-2006 (J. Benavides, J.L. Fernández \& N. Villagra, eds.), Comillas, Madrid. 
VV.AA. (2007): Evolución conceptual y práctica de una gestión responsable. Memoria Académica. Curso 2006-2007 (A. Bajo \& N. Villagra, eds.), Comillas, Madrid.

VV.AA. (2008): Reflexiones en torno a la Responsabilidad Social en el ámbito de la globalización. Memoria Académica. Curso 2007-2008 (A. Bajo \& N. Villagra, eds.) Comillas, Madrid.

VV.AA. (2008): Asociación Española de Anunciantes: La gestión Publicitaria y de comunicación en los anunciantes, AEA, Madrid, 2008.

VV.AA. (2009): Valores para uma gestión socialmente responsable. Memoria Académica. Curso 2008-2009 (A. Bajo \& N. Villagra, eds.), Comillas, Madrid.

VV.AA. (2009): Ética Pensada y compartida. Libro homenaje a Augusto Hortal, (C. Cañón \& A. Villar, eds.), Universidad Comillas, Madrid.

\section{CONSULTAS EN INTERNET:}

www.reputacioncorporativa.org/tendencias/corporate-reputation-innthecompany .agenda

www.sostenibilidad2010.solmelia.com.

www.shakletongroup.com/es/porfolio,

[Recibido: 11 de junio de 2011. Aceptado: 10 de enero de 2012]. 